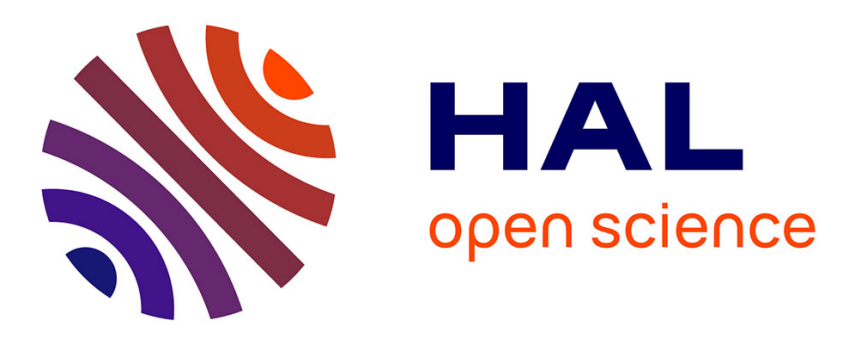

\title{
Mechanical characterization of carbonitrided steel with spherical indentation using the average representative strain
}

Charbel Moussa, Olivier Bartier, Xavier Hernot, Gérard Mauvoisin, Jean-Marc Collin, Guillaume Delattre

\section{To cite this version:}

Charbel Moussa, Olivier Bartier, Xavier Hernot, Gérard Mauvoisin, Jean-Marc Collin, et al.. Mechanical characterization of carbonitrided steel with spherical indentation using the average representative strain. Materials \& Design, 2016, 89, pp.1191-1198. 10.1016/j.matdes.2015.10.067 . hal-01247082

HAL Id: hal-01247082

https://hal-mines-paristech.archives-ouvertes.fr/hal-01247082

Submitted on 14 Jan 2016

HAL is a multi-disciplinary open access archive for the deposit and dissemination of scientific research documents, whether they are published or not. The documents may come from teaching and research institutions in France or abroad, or from public or private research centers.
L'archive ouverte pluridisciplinaire HAL, est destinée au dépôt et à la diffusion de documents scientifiques de niveau recherche, publiés ou non, émanant des établissements d'enseignement et de recherche français ou étrangers, des laboratoires publics ou privés. 


\title{
Mechanical characterization of carbonitrided steel with spherical indentation using the average representative strain
}

\author{
Charbel Moussa ${ }^{\mathrm{a}}$, Olivier Bartier ${ }^{\mathrm{a}}$, Xavier Hernot ${ }^{\mathrm{a}}$, Gérard Mauvoisin ${ }^{\mathrm{a}}$, Jean-Marc Collin ${ }^{\mathrm{a}, \mathrm{b}, *}$, \\ Guillaume Delattre ${ }^{\mathrm{c}}$ \\ ${ }^{a}$ LGCGM, EA 3913, INSA de Rennes, 20 Avenue des Buttes de Coësmes, 35708 Rennes Cedex 7, France \\ ${ }^{\mathrm{b}}$ Université de Nantes, 1 quai de Tourville, BP 13522, 44035 Nantes Cedex 1, France \\ ${ }^{\mathrm{c}}$ FAURECIA Automotive seating, Le pont de Vère, 61100 Caligny, France
}

\begin{abstract}
This paper investigates the identification of mechanical properties of carbonitrided steels using the spherical indentation test. The proposed procedure consists in performing the Vickers microindentation hardness test across the carbonitrided steel in order to obtain the thickness of the hardened layers. Thus, with the assumption of a linear variation of the plastic properties in the intermediate layers between surface and substrate, two spherical macroindentation tests, performed on the substrate and on the surface of the carbonitrided steel, are necessary to identify the work hardening laws' variation through the thickness of the carbonitrided steel. The proposed method does not call for inverse analysis but is based on the use of a database of finite element simulation $F-h$ curves obtained by simulating indentation tests on the surface of various pseudo-carbonitrided materials. The advantage of this method compared to those based on inverse analysis is that it allows a representative strain and a confidence domain of the solution to be determined. The confidence domain of the identified solution takes into account the experimental imprecision of the indentation test and of the case depth variability often encountered in carbonitrided parts.
\end{abstract}

Keywords: Spherical indentation, average representative strain, carbonitrided steels, hardening law, mechanical characterization, confidence domain

* Corresponding author: jean-marc.collin@univ-nantes.fr, telephone +33228092029

\section{Introduction}

Identification of the mechanical properties of non-homogeneous materials have become an important challenge during the last decades. Knowledge of the hardening laws of these materials is necessary in order to design industrial products. An important material family is the so- called plastically graded materials (PGMs). Among PGMs, carbonitrided steels are used for many industrial applications. These materials present a variation of the hardness with the depth from the surface while the elastic properties remain constant [1-4].

Using classical tensile tests on PGM does not provide a good prediction of the changes of the mechanical properties with the depth. Indeed, the treated volume of material is negligible compared to the volume of the non treated part of a standard tensile sample. A local mechanical test is thus necessary in order to obtain accurate values of the mechanical properties. One of these tests is the instrumented indentation which has been studied for several decades. Its applications in mechanical characterization have been demonstrated in a great number of papers [5-15]. In most of these papers, the Hollomon's power law given in Eq. (1) has been used to model the elastic-plastic behaviour: 


$$
\left\{\begin{array}{l}
\sigma=E \varepsilon ; \sigma<\sigma_{y} \\
\sigma=\sigma_{y}^{1-n} E^{n} \varepsilon^{n} ; \sigma \geq \sigma_{y}
\end{array}\right.
$$

where $E$ is the Young modulus, $\sigma_{y}$ the yield stress and $n$ the strain hardening exponent.

A great number of papers concern the determination of mechanical properties of homogeneous materials. In this case, the determination of the mechanical parameters of Eq. (1) from the indentation curve can be done using the minimization between indentation experiments and models of instrumented indentation obtained by numerical simulations [511]. The main advantages of this approach are the simplicity of implementation and the instant results. However, the proposed models depend on the behaviour law, the geometry of the indenter and many other assumptions depending on each study. Moreover, the application of these methods is often limited to particular cases of bulk homogeneous materials and for a specific indenter geometry.

In order to apply the indentation test whatever the behaviour law, sample heterogeneity or indenter geometry, a second approach can be used. This approach is called "inverse analysis" where the minimization is directly made between experiments and finite element (FE) simulations. Several authors [12-15] have proposed to apply the inverse analysis approach on indentation experiments in order to determine some mechanical properties.

The two approaches presented above are, for most of them, purely phenomenological.

However, a great number of papers have explained the physical phenomenon involved during an indentation test. The indentation test induces a complex tri-axial mechanical behaviour. This is the reason why the concept of representative strain has been introduced by Tabor [16]. The aim of using the representative strain concept is to make the link between the material response to the indentation test and the material hardening law. For conical indenters, the representative strain is constant whatever the applied load, which explains the non-uniqueness of the solution for the identification of the hardening law [17-20]. For conical indentation, all the stress-strain curves that intersect at a point of the abscissa which corresponds to the representative strain, lead to identical indentation curves [20]. For spherical indentation, representative strain depends on the indentation depth. Thus, the problem of uniqueness of the solution can be solved [17]. The concept of representative strain is still an open question and a great number of formulations and definitions have been proposed [7-8-18-19-20].

In a previous paper, Moussa et al. [21] proposed a new method to determine the hardening law of homogenous materials using the average representative strain concept. The advantage of this concept is that the representative strain is directly obtained from the response of the indentation test. Using different penetration depths provides the range of strain for which the identified hardening law is valid. Thus, it allows the determination of a confidence domain taking into account experimental imprecision and material heterogeneity. However, in the reference [21], only bulk homogenous materials were studied.

A complete overview of the theory realized by Moussa et al. [22] has shown that, compared to homogenous materials, few studies have been done to characterize the mechanical behaviour of PGM with the indentation test. They have demonstrated that most of the methods proposed in the literature are based on restrictive assumptions which are not verified for all PGMs. Some of the methods even consider that the strain hardening exponent remains constant between surface and substrate [23-25], which cannot be physically justified. For 
those reasons, the authors previously [22] proposed to characterize the mechanical behaviour of two carbonitrided steels using spherical indentation and the "inverse analysis" approach. In this paper, a methodology was proposed, based on the assumption of a linear variation of the hardening law from the surface to the substrate. This assumption has been justified and validated by Moussa et al. [26].

The aim of this work is to generalize the concept of average representative strain, previously proposed for homogenous materials, to PGMs and to apply this to carbonitrided steels. This concept will be used in order to define a confidence domain around the identified hardening laws. Moreover, a numerical study of the sample behaviour under the indenter will show the non influence of friction.

\section{Characterization method}

In previous studies $[22,26]$, a procedure to characterize PGMs was presented. This procedure can be described as follows: "The decreasing hardness profile of carbonitrided steels can be approximated by three zones. In the first zone of thickness $e_{1}$, the hardness is constant and equal to the surface hardness. In the second zone of thickness $e_{2}$, the hardness presents a regular decrease and can be approximated by an inclined line. Finally, the third zone corresponds to the substrate (core), where the hardness is constant. The variation of the plastic properties is approximated in the same way" [26]. This variation, illustrated in Fig. 1, can be described by the following equation

$$
\begin{array}{lrl}
\sigma=\sigma^{\text {surface }} & \text { for } z<e_{1} \\
\sigma=\sigma^{\text {substrate }}+\frac{\sigma^{\text {surface }}-\sigma^{\text {substrate }}}{e_{2}}\left(e_{2}+e_{1}-z\right) & \text { for } e_{1}<z<e_{2}+e_{1} \\
\sigma=\sigma^{\text {substrate }} & \text { for } z>e_{2}+e_{1}
\end{array}
$$

Where, for each plastic strain, $\sigma^{\text {surface }}$ and $\sigma^{\text {substrate }}$ are the stress of the surface and of the substrate respectively, $\mathrm{z}$ is the distance from surface across the thickness of the sample and $e_{1}$ and $e_{2}$ are the thicknesses of the surface and intermediate layers respectively.

With this approximation, the characterization of the carbonitrided steels is reduced to the identification of the hardening law of the surface, the hardening law of the substrate and the thicknesses $e_{1}$ and $e_{2}$. The present procedure is divided into the three steps illustrated in Fig. 1. The first step consists of applying a spherical indentation test to the substrate. Since the volume of the substrate is large enough, it can be considered as a homogenous material and the material parameters set $\left(\sigma_{y s u b s t r a t e}, n_{\text {substrate }}\right)$ of the hardening law of the substrate material can be identified. The second step consists of estimating the values of thicknesses $e_{1}$ and $e_{2}$ from the hardness profile. The third step consists of applying a spherical indentation test on the surface. Since the hardening laws of the substrate, $e_{1}$ and $e_{2}$ are identified, the only unknown values left to identify are the material parameters set $\left(\sigma_{\text {ysurface }}, n_{\text {surface }}\right)$ of the hardening law of the surface. Following the proposed procedure, the problem is divided into three steps with two unknowns for each.

The described three steps approach was presented previously.[22, 26] and applied with inverse analysis using SiDoLo software [27]. In the present paper, these three steps of characterization were performed using the identification method proposed [21, 28] for homogeneous materials. The simulation of the spherical indentation test was performed with the FE method using the commercial FE software ABAQUS. Simulations were done using an axisymmetric mesh built with 18,400 elements. The hardening law used in this paper is the Hollomon's power law given in Eq. (1) associated to a Von-Mises plasticity criterion. 


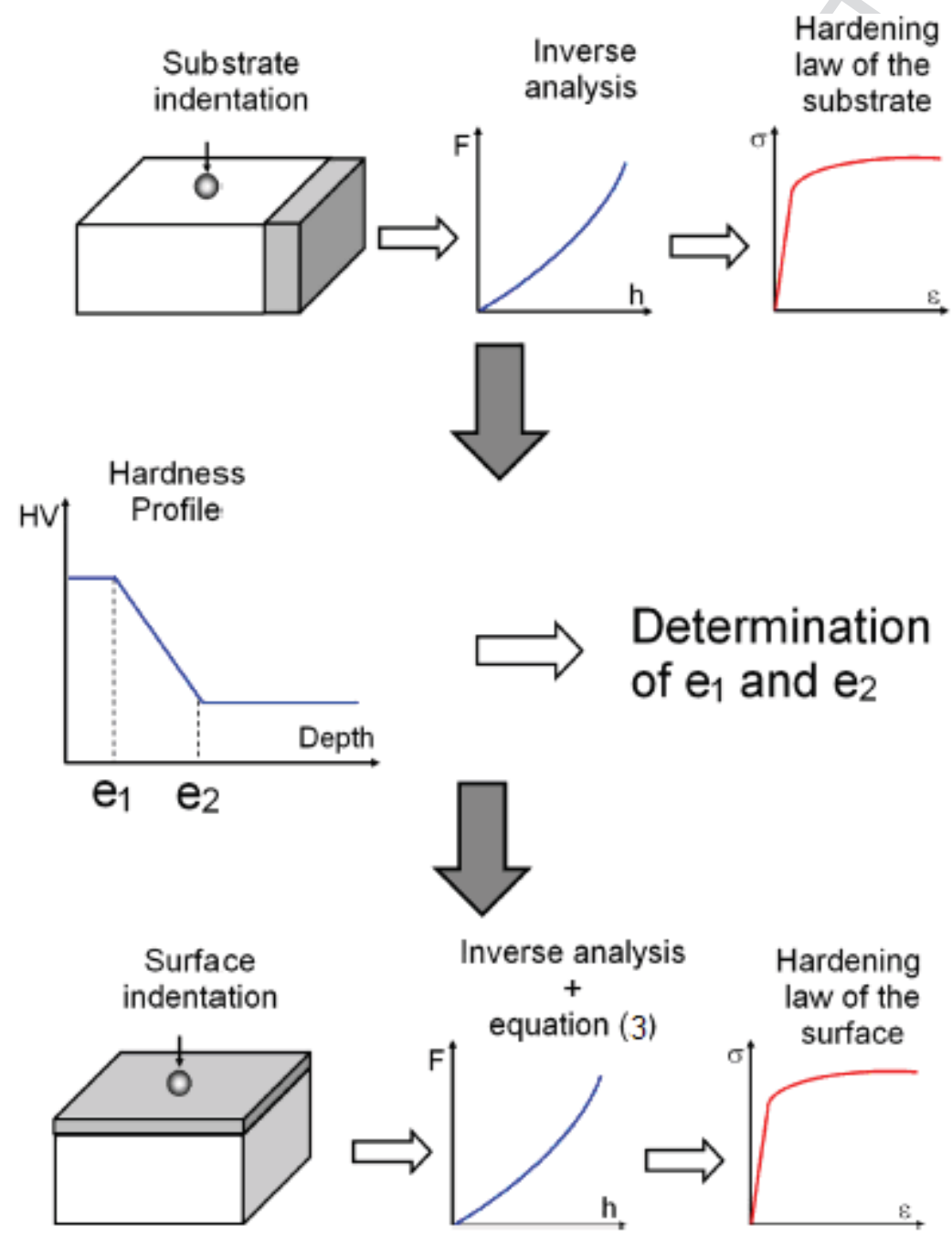

Figure 1: Method for the characterization of carbonitrided steel

\section{Application of a characterization methodology based on the average representative} strain. [21]

\subsection{Material and experimental parameters}

In this paper, the studied material is the $\mathrm{C} 12$-carbonitrided steel for which the hardening profile and metallographic analysis have been presented in a previous paper [26]. Before performing the carbonitriding process, the specimens were carefully polished using fine emery papers (up to 1200 grit) to avoid uncertainties due to roughness when performing the indentation test on the surface of the carbonitrided steel. The carbonitrided specimens were cut out and the sections were polished using fine emery papers (up to 1200 grit) and diamond suspensions $(6$ and $3 \mu \mathrm{m})$ before performing the Vickers micro hardness tests and the metallographic analysis. Vickers micro hardness profile of the transverse cross section of the 
carbonitrided steel using a $200 \mathrm{~g}$ load provided the values for the thicknesses $e_{1}=0.06 \mathrm{~mm}$ and $e_{2}=0.29 \mathrm{~mm}[26]$.

The metallographic analysis showed that the microstructure of the carbonitrided layers consists of a martensite or bainite matrix containing troostite particles in the former austenite grain boundaries. This analysis also shows that the microstructure of the substrate mainly contains acicular ferrite and pearlite grains. The size of the former austenitic grains is smaller than $50 \mu \mathrm{m}$. The diagonal lengths of the Vickers imprints in the range from $20 \mu \mathrm{m}$ to $40 \mu \mathrm{m}$ lead to hardness of the order of $700 \mathrm{HV}$ and $220 \mathrm{HV}$ for the surface and the substrate of the carbonitrided steel, respectively [26].

The spherical indentation tests were carried out using an indentation instrumented bench developed within our laboratory. The system's resolutions are $0.02 \mathrm{~N}$ and $0.02 \mu \mathrm{m}$ for load and displacement respectively. The tests were carried out with a spherical indenter of radius $\mathrm{R}=0.5$ $\mathrm{mm}$, and the displacement rate was about $2 \mu \mathrm{m} / \mathrm{s}$. The maximum applied load was equal to $900 \mathrm{~N}$. The diameter of the residual imprint performed on the substrate after applying $900 \mathrm{~N}$ was about $730 \mu \mathrm{m}$. Compared to the grain size of the microstructure, the size of the imprint is large enough to avoid structural heterogeneity problems. Concerning the spherical indentation test performed on the surface of the carbonitrided steel, the plastic zone depth is larger than the thickness of the carbonitrided layers when applying a maximum applied load of $900 \mathrm{~N}$. This indicates that the response of the indentation test is influenced by the surface, the intermediate layers and the substrate.

\subsection{Characterization of the substrate}

In previous studies [21, 28] a characterization method with spherical indentation for homogenous materials was proposed. This method was used to identify the hardening law of the substrate of the C12-carbonitrided steel. The fundamental concepts used in order to determine the mechanical properties of the substrate fully illustrated in previous papers [21, $28]$ are given in the following paragraph.

The method consists of calculating the error between the average experimental $F$ - $h$ curve (average load for every penetration depth) and a number of $F-h$ curves obtained from $\mathrm{FE}$ simulation. In order to quantify the difference between two indentation curves, the root mean square error, Eq. 3, was used:

$$
E_{R M S}\left(h_{\max } / R\right)=\sqrt{\frac{1}{h_{\max }} \int_{0}^{h_{\max }}\left(F_{1}-F_{2}\right)^{2} d h}
$$

Where $R$ is the spherical indenter radius $(R=0.5 \mathrm{~mm}), h$ is the penetration depth, $h_{\max }$ is the maximal penetration depth and $F_{1}$ and $F_{2}$ are the load for the two considered curves. To use this method, a database of FE simulation indentation curves was built up with 3,872 $F$ - $h$ curves. The corresponding Hollomon hardening law parameter sets $\left(\sigma_{y}, n\right)$ were presented in a previous paper [28]. Six indentation tests were done on three different samples of the carbonitrided $\mathrm{C} 12$ steel. The average curve was only used to identify the substrate of the carbonitrided $\mathrm{C} 12$ steel. The characterization procedure consists of calculating the difference, using $E_{R M S}$ (Eq. 3), between the average experimental $F$ - $h$ curve and the $F$ - $h$ curves of the database. The presence of a valley, in which small variation of $E_{R M S}$ occurs, was shown in our 
previous paper [28]. This distribution takes the form of a cone with an elliptical base in the $[k$, $n]$ diagram with $k$ equal to:

$$
k=(1-n) \ln \left(\frac{\sigma_{y}}{E}\right)
$$

It should be noticed that the elliptical cone form was assumed to be the form of the ERMS distribution near the solution, i.e where the valley exists. For this reason, $E_{\text {critical }}$ was defined in order to use only the material parameter sets that are near the solution to correctly determine the parameters of the elliptical cone. In this study $E_{\text {critical }}$ was set to $30 \mathrm{~N}$.

The coordinates of the elliptical cone summit, corresponding to the identified solution and the direction of the principal axis of the ellipse in $[\mathrm{k}, \mathrm{n}]$ the diagram, indicates the average representative strain $\varepsilon_{a R}$. From this procedure, the material parameter set $\left(\sigma_{y}, n\right)$ that represents the solution was identified and the average representative strain $\varepsilon_{a R}$ was determined. $\sigma_{y}=315$ Mpa and $n=0.166$ corresponding to $\varepsilon_{a R}=0.054$ were identified for the substrate.

In order to take into account the material heterogeneity and the experimental imprecision, the gap between the average curve and each one of the experimental curves was quantified using ERMS, Eq. 3. For the case of the substrate of the carbonitrided C12 steel, the maximal value of experimental gap is equal to $7.3 \mathrm{~N}$. The isovalue of $7.3 \mathrm{~N}$ was used to determine the confidence domain $[21,28]$. All the Hollomon hardening laws that are located inside the confidence domain will lead to $F-h$ curves that give an ERMS value with the average experimental $F-h$ curve smaller than $7.3 \mathrm{~N}$. The identified hardening law, $\left(\sigma_{y}=315 \mathrm{Mpa}\right.$, $n=0.166$ ) and the confidence domain are presented in Fig. 2. The confidence domain is narrow because the experimental $F-h$ curves are very close.

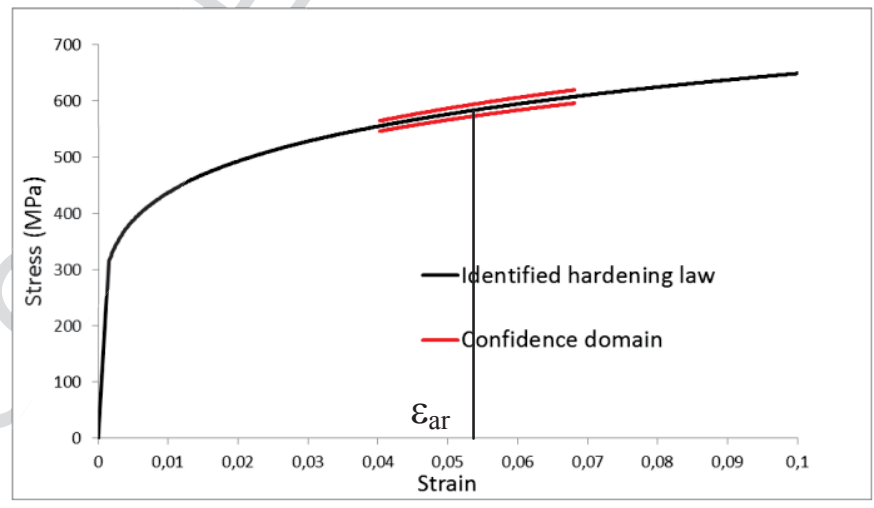

Figure 2: Identified hardening law for the substrate with the confidence domain

\subsection{Characterization of the surface}

\section{3.a. Identification of the hardening law of the surface}

As mentioned above, the thicknesses $e_{1}$ and $e_{2}$ were estimated from the hardness profile. For the studied $\mathrm{C} 12$ carbonitrided steel, $e_{1}=0.06 \mathrm{~mm}$ and $e_{2}=0.29 \mathrm{~mm}$ [26]. At this stage, since the material parameter set $\left(\sigma_{y}, n\right)$ of the substrate was identified, the two unknowns are the material parameter sets $\left(\sigma_{y}, n\right)$ of the surface.

In a previous study [26], the identification of the material parameter set $\left(\sigma_{y}, n\right)$ of the surface was calculated with inverse analysis. In the present study, this identification was done using the method that was used for the substrate (paragraph 3.1). In order to build up a database of FE simulation $F$ - $h$ curves of the surface, the material parameter set identified for the substrate, 
$\left(\sigma_{y}=315 \mathrm{Mpa}, n=0.166\right)$ and the thicknesses, $e_{1}=0.06 \mathrm{~mm}$ and $e_{2}=0.35 \mathrm{~mm}$ were fixed. The material parameters sets chosen to build up the database are presented in Table1.

The $F$ - $h$ curves obtained on the surface of three samples are presented in Fig. 3. As we can see, for the case of the surface of the carbonitrided C12 steel the reproducibility of the curves is not as good as for the case of the substrate. This observation was expected since when the indentation test was done on the surface, the intermediate zone and the substrate influence the behaviour of the material. Therefore the $F$ - $h$ curves of the surface are influenced by the three parts of the material: surface, intermediate layer and substrate. The differences observed between the three samples for each one of these three layers and for the hardness profile explain the differences observed in the $F$ - $h$ curves.

\begin{tabular}{cccccccc}
\multicolumn{8}{c}{$\sigma_{y}(\mathrm{MPa})$} \\
\hline \hline 1570 & 1600 & 1630 & 1660 & 1690 & 1720 & 1750 & 1780 \\
1810 & 1840 & 1870 & 1900 & 1930 & 1960 & 1990 & 2020 \\
2050 & 2080 & 2110 & 2140 & 2170 & 2200 & 2230 & 2260 \\
2290 & \multicolumn{7}{c}{$n$} \\
\hline \hline \multicolumn{8}{c}{$n$} \\
\hline \hline 0.0 & 0.005 & 0.01 & 0.015 & 0.02 & 0.025 & 0.03 & 0.035 \\
0.04 & 0.045 & 0.05 & 0.055 & 0.06 & 0.065 & 0.07 & 0.075 \\
0.08 & 0.085 & 0.09 & 0.095 & 0.1 & 0.105 & 0.11 & 0.115 \\
0.12 & 0.125 & 0.13 & 0.135 & 0.14 & 0.145 & 0.15 & 0.155 \\
0.16 & 0.165 & 0.17 & 0.175 & 0.18 & 0.185 & 0.19 & 0.195 \\
0.2 & 0.205 & & & & & &
\end{tabular}

Table 1: Material Plastic properties used for the finite element simulations of the surface

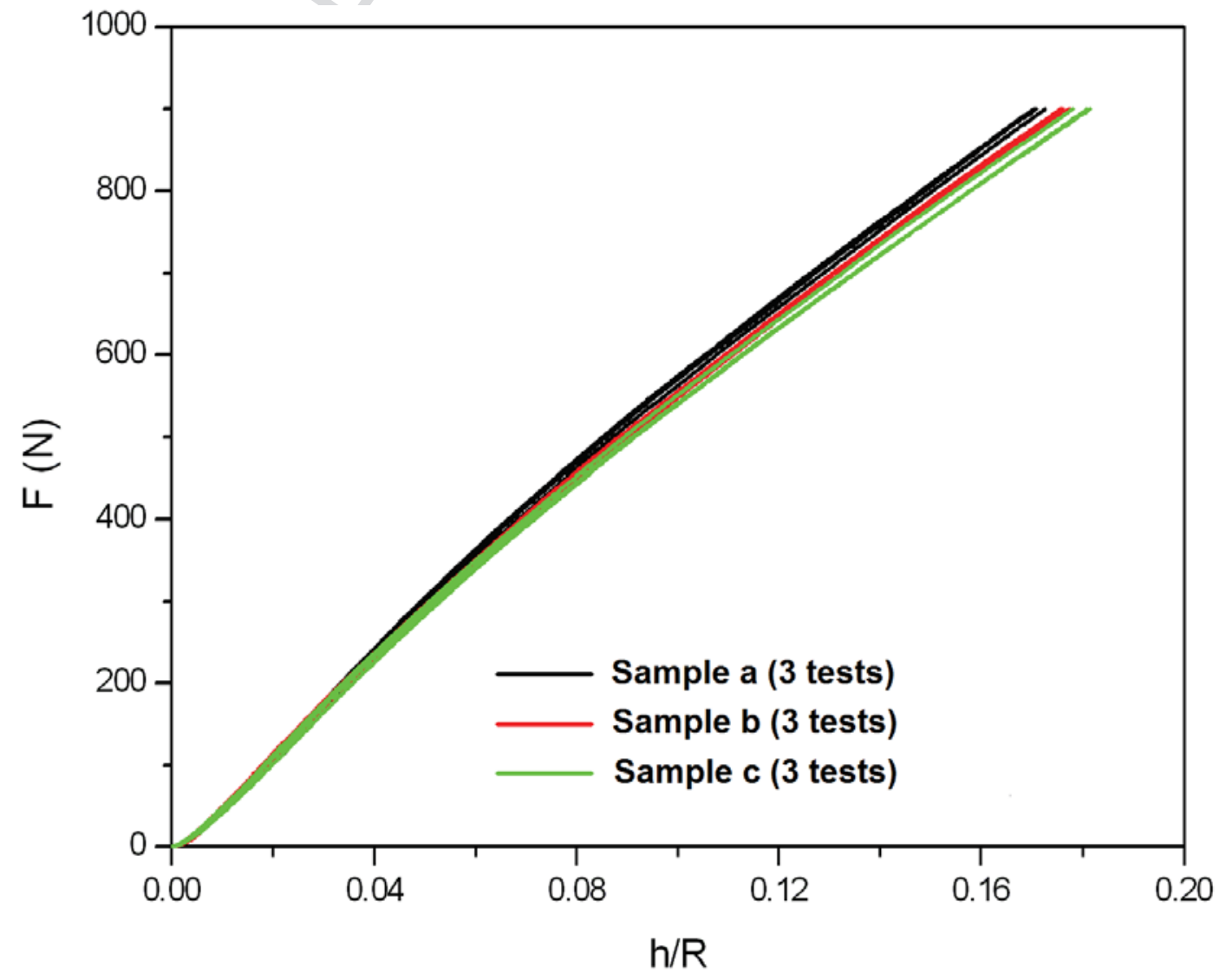


Figure 3: Experimental $F$ - $h$ curves on the C12-carbonitrided steel surface

The average curve of the nine experimental curves obtained on the surface was used to identify the surface material parameters. The ERMS was calculated between the average experimental curve and each one of the $F-h$ curves of the database. The ERMS distribution obtained is presented in Figs. 4-5.

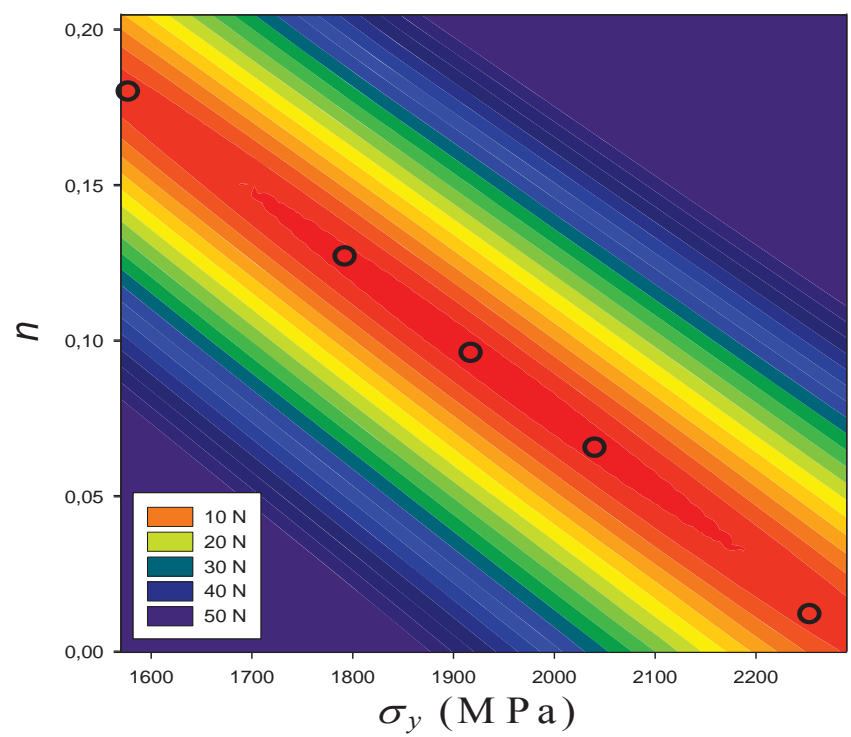

Figure 4 : Isovalues for the nine experimental curves in the $\left(\sigma_{y}, n\right)$ space

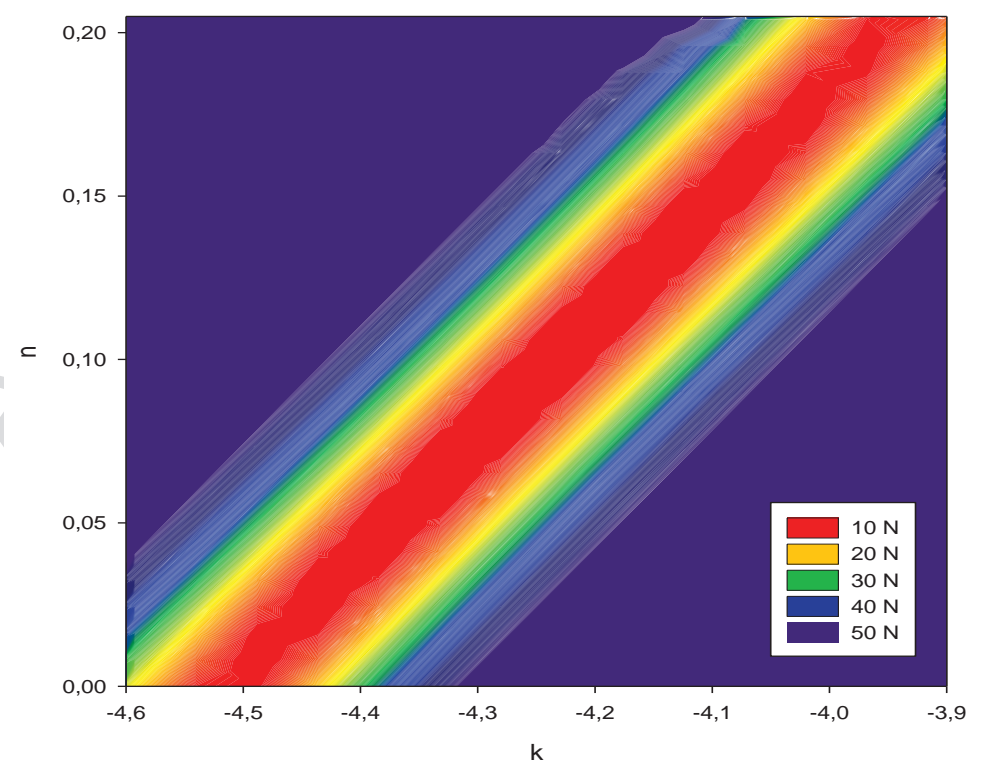

Figure 5 : Isovalues for the nine experimental curves in the $(k, n)$ space

It is shown in Figs. 4-5 that the ERMS distribution obtained for a PGM (indentation on the surface of the carbonitrided $\mathrm{C} 12$ steel) takes the same form as for the homogenous material. This observation means that the previous identification method (based on the cone with the elliptical base) proposed for the homogenous material can be applied for the case of PGMs. Figs. 4-5 also show that the valley is much larger than the one obtained for homogenous materials [28]. This observation means that the sensitivity of the $F-h$ curve obtained for PGM is smaller than that of the $F-h$ curve obtained for homogenous material. This result was 
somehow expected since the database was built up with a fixed the hardening law of the substrate, which means that the sensitivity of only a part of the plastified volume under the indenter is tested.

The comparison between the ERMS distribution obtained from the database and the one obtained from the equations of the cone with the elliptical base is presented in Fig. 6. In this figure, it is clearly shown that the ellipse distribution superimposes onto the ERMS distribution. The result given in this figure proves that the ERMS distribution takes the form of a cone with an elliptical base. The small differences observed in Fig. 6 are mainly due to the lack of FE simulations in the database.

From the equation of the cone with the elliptical base $[21,28]$, the mechanical properties of the surface $\sigma_{y 0}=1916.6 \mathrm{MPa}$ and $n_{0}=0.0961$ were determined. The same result was obtained when inverse analysis was used previously. [26]. tThe results in that study, obtained when using inverse analysis, were validated by using an instrumented roller test. Thus, we can consider that the hardening laws for the carbonitrided steels identified in this paper enable the material response of the $\mathrm{C} 12$ carbonitrided steel, under different indentation load conditions, to be predicted.

In the proposed methodology, the third step consists in performing spherical indentation on the hardened surface of the material with the aim of obtaining a plastic zone of thickness higher than the thickness of the hardened layer. From this step, the work hardening law of the hardened layer is obtained. In our opinion, the proposed methodology used with the experimental condition given in the paper, i.e. $R=0.5 \mathrm{~mm}, F=900 \mathrm{~N}$, can be applied to standard carburized, nitrided or carbonitrided, steels of hardened layer thicknesses smaller than 1.5 mm.

If we want to use the proposed method to accurately characterize thin films of thickness less than $0.05 \mathrm{~mm}$, an indenter with a radius smaller than $0.5 \mathrm{~mm}$ is required. However, small perfect indenter geometry is quite difficult to manufacture, especially in the nano and micro scales. Indentation curves obtained with imperfect indenter geometry can show great differences to those obtained with assumed perfect indenter geometry, thereby leading to erroneous data exploitation results. In this case, the authors recommend using the correction method proposed in ref. [29]. 


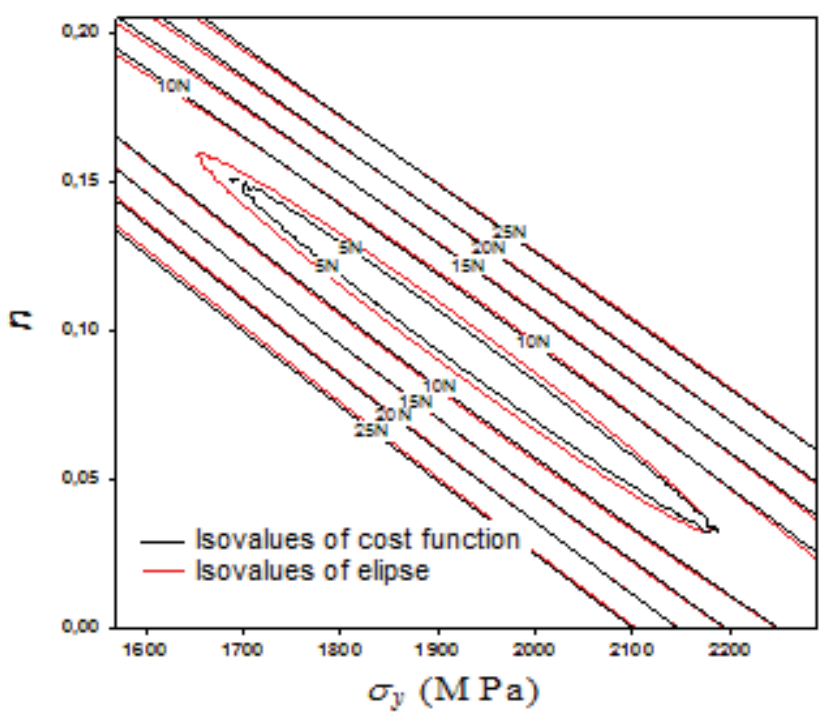

Figure 6 : Comparison between isovalues calculated with cost functions and the ones calculated with the ellipse equations.

\section{3.b. Average representative strain}

Since the ERMS distribution takes the form of a cone with an elliptical base, in a same way as for homogenous materials, an average representative strain can be defined for the PGM. The material parameter sets $\left(\sigma_{y}, n\right)$ located at the bottom of the valley give hardening laws that lead to $F$ - $h$ curves which are very close to the $F$ - $h$ experimental curve. Similarly to the case of homogenous materials [21], all the hardening laws intersect in a same point. We define the "average representative strain" $\varepsilon_{\text {ar }}$ as the abscissa of the intersection point (Fig. 7). The value $\varepsilon_{a r}=0.0615$ was analytically determined for the studied case [21, 28]. All the Hollomon hardening laws that intersect the stress-strain curve corresponding to the solution at $\left[\varepsilon_{a r}, \sigma_{\mathrm{ar}}\right]$ lead to indentation curves close to the indentation curve corresponding to the solution. Hence, the $F$ - $h$ curve obtained for a PGM is mostly influenced by the part of the hardening law which is located around $\varepsilon_{a r}$. When a material is characterized using the $F$ - $h$ curve, it is this part of the Hollomon hardening law that is mostly characterized and better identified. 


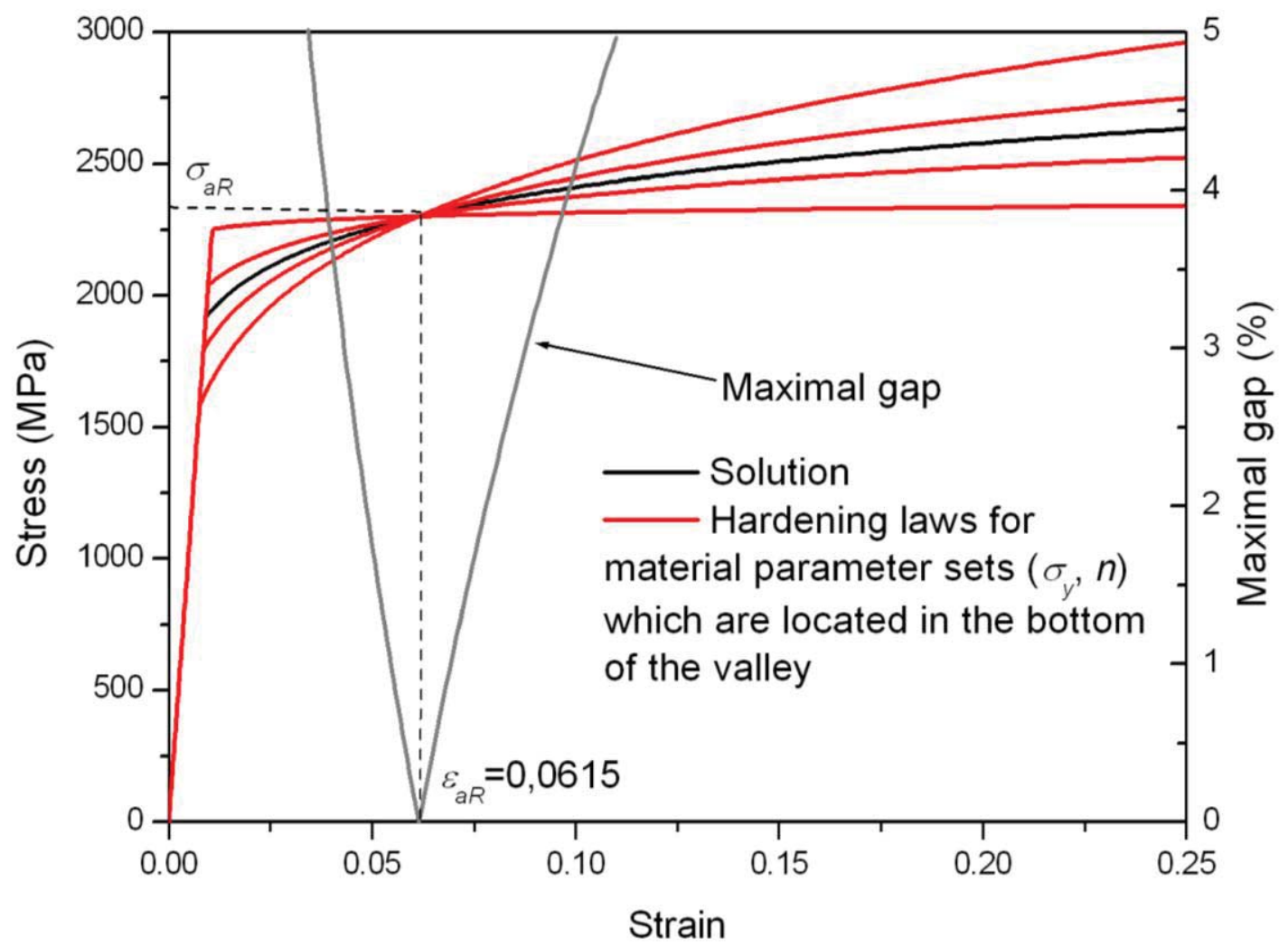

Figure 7: Comparison between the identified hardening law and that calculated from the set of parameters which are at the bottom of the valley.

\section{3.c. Solution domain}

In the identification method developed for the case of homogenous materials, a confidence domain, which allows the taking into account of experimental imprecision and material heterogeneity, was defined. In this paragraph the confidence domain is determined for the carbonitrided steel. The values of ERMS calculated between the average experimental curve and each one of the nine experimental curves, using Eq. 3, are presented in Table 2.

\section{ERMS (N) for hmax/R=0.17}

\begin{tabular}{ccc||ccc||ccc||c}
\hline \hline \multicolumn{3}{c||}{ Sample a } & \multicolumn{3}{c||}{ Sample b } & \multicolumn{3}{c|}{ Sample c } & \\
\hline \hline Test 1 & Test 2 & Test 3 & Test 1 & Test 2 & Test 3 & Test 1 & Test 2 & Test 3 & Maximum \\
13.5 & 7.8 & 16.6 & 6.6 & 2.6 & 1.5 & 5.0 & 14.6 & 12.9 & 16.6
\end{tabular}

Table 2: Values of the cost function for the nine curves for $h_{\max } / R=0.17$.

In order to take into account experimental imprecision and material heterogeneity, the maximal value of Table $2,16.6 \mathrm{~N}$, was considered. The isovalue corresponding to this value is presented in Fig. 8. In this figure the material parameter set identified for the average curve is presented by a black dot. 


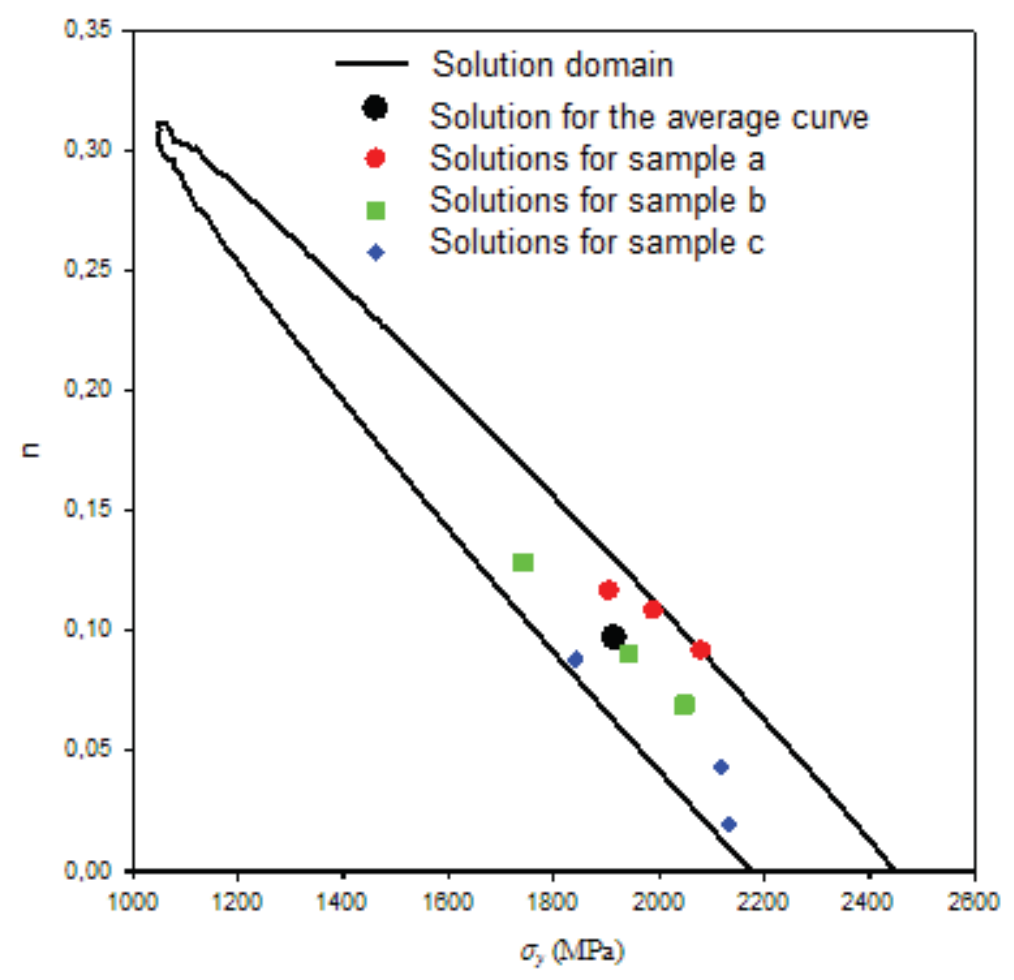

Figure 8: Solution domain for the nine experimental tests for $h_{\max } / R=0.17$

All the material parameter sets $\left(\sigma_{y}, n\right)$ located inside the domain limited with this isovalue give hardening laws that lead to $F$ - $h$ curves with ERMS values smaller than $16.6 N$. Therefore all material parameter sets $\left(\sigma_{y}, n\right)$ located inside this domain should be considered as solutions, because this value is the maximal gap between experimental curves. The domain presented in Fig. 8 is defined as the solution domain.

Each one of the nine $F-h$ curves was used to identify the Hollomon hardening law of the surface. The identified parameter sets $\left(\sigma_{y}, n\right)$, see Table 3 , are presented with colored dots in Fig. 8. This figure shows that these colored dots are all located inside the solution domain. This result validates the fact that the solution domain regroups all possible solutions.

$\mathbf{h m a x} / \mathbf{R}=\mathbf{0 . 1 7}$

\begin{tabular}{cccc||ccc||ccc||c}
\hline \hline & \multicolumn{3}{c||}{ Sample a } & \multicolumn{3}{c||}{ Sample b } & \multicolumn{3}{c|}{ Sample c } & \multicolumn{2}{c}{$\begin{array}{c}\text { Average } \\
\text { curve }\end{array}$} \\
\hline \hline & Test 1 & Test 2 & Test 3 & Test 1 & Test 2 & Test 3 & Test 1 & Test 2 & Test 3 & \\
$\begin{array}{c}\boldsymbol{\sigma}_{\mathbf{y}} \\
\mathbf{M P a} \\
\mathbf{n}\end{array}$ & 1984.6 & 1901.0 & 2083.3 & 1740.0 & 2047.4 & 1941.2 & 2115.8 & 1840.3 & 2131.9 & 1916.6 \\
& 0.1091 & 0.1164 & 0.0927 & 0.1280 & 0.0691 & 0.0901 & 0.0431 & 0.0879 & 0.0190 & 0.0961
\end{tabular}

Table 3: Identified mechanical properties for the nine experimental curves

\section{3.d. Confidence domain}

The confidence domain, developed in previous studies for the case of homogenous materials $[21,28]$, regroups all possible solutions in the stress-strain diagram. This domain was obtained from the four points located on the four summits of the solution domain, see Fig. 9.a. 
Around the representative parameter set $\left[\varepsilon_{a r}, \sigma_{\mathrm{ar}}\right]$ the confidence domain is limited by the hardening laws corresponding to points $b$ and $d$ presented in Fig. 9.a, determined with the following equations:

point b: $\begin{aligned} & k=k_{0}-E_{R M S} Y \sin \theta_{a R} \\ & n=n_{0}+E_{R M S} Y \cos \theta_{a R}\end{aligned} \quad$ point d: $\begin{aligned} & k=k_{0}+E_{R M S} Y \sin \theta_{a R} \\ & n=n_{0}-E_{R M S} Y \cos \theta_{a R}\end{aligned}$

The confidence domain is defined between $\varepsilon_{a b}$ and $\varepsilon_{b c}$ defined as follow:

$\varepsilon_{a b}=\varepsilon_{c d} \approx \varepsilon_{a R}-\Delta \varepsilon_{a R}$

$\varepsilon_{b c}=\varepsilon_{d a} \approx \varepsilon_{a R}+\Delta \varepsilon_{a R}$

with

$\Delta \varepsilon_{a R}=\varepsilon_{a R}\left(1+\left(\ln \varepsilon_{a R}\right)^{2}\right) \arctan \frac{Y}{X}$

In the present study, we can see in Fig. 9.a that a part of the solution domain corresponds to a negative value of $n$, which is not realistic for the plasticity of cold metals. Therefore the solution domain should be reduced in order to exclude the hardening laws that have a negative value of $n$. As we can see in Fig. 9.a, point c should be replaced with points c' and c". The hardening laws of the points $a, b, c^{\prime}, c^{\prime}$ ' and d are presented in Fig. 9.b. As for the average representative strain, the direction of the segment [c'c"] allows an equivalent value of strain to be determined. Since the segment [c'c"] is horizontal, the equivalent strain is infinite.

For the case of the carbonitrided steel, the confidence domain corresponding to the solution domain can be thus determined, see Fig. 9.b.

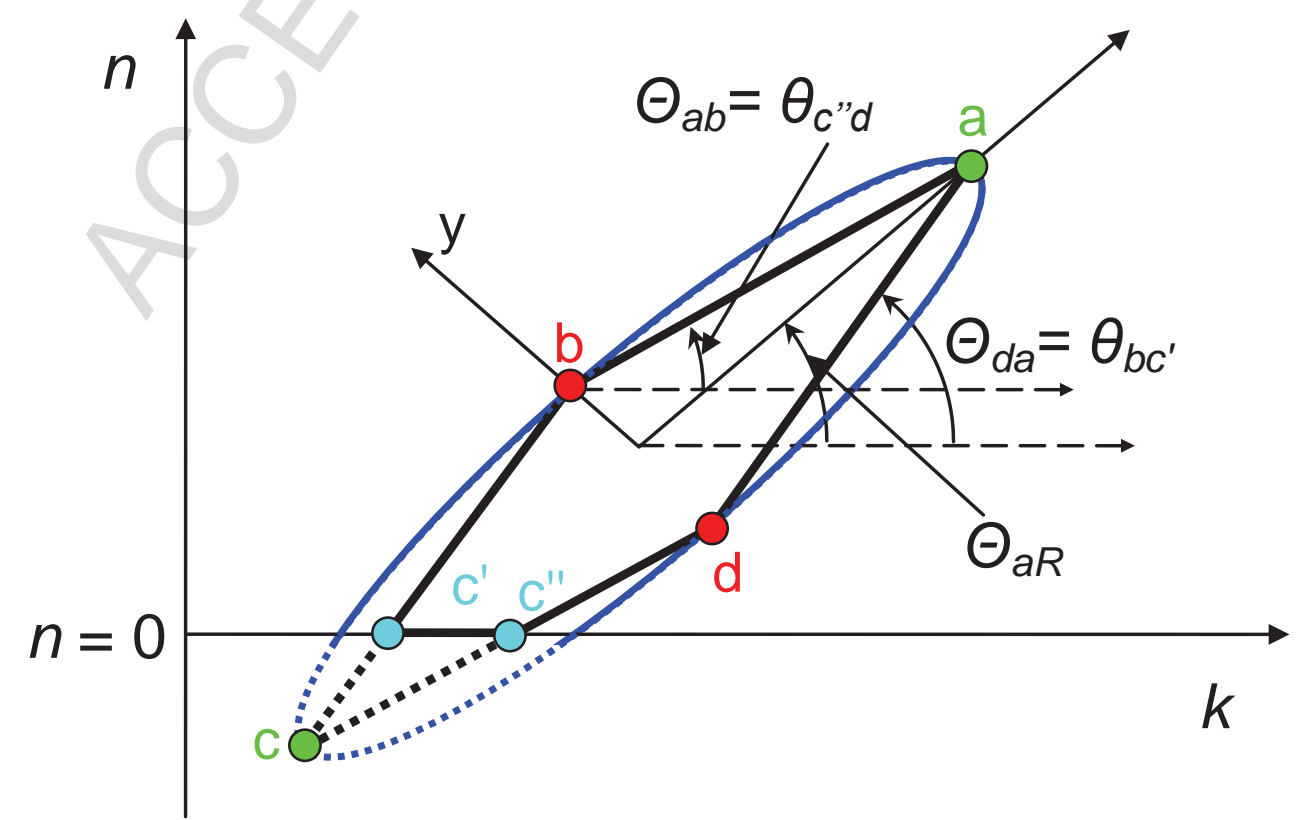

Figure 9.a : Solution domain for the surface 


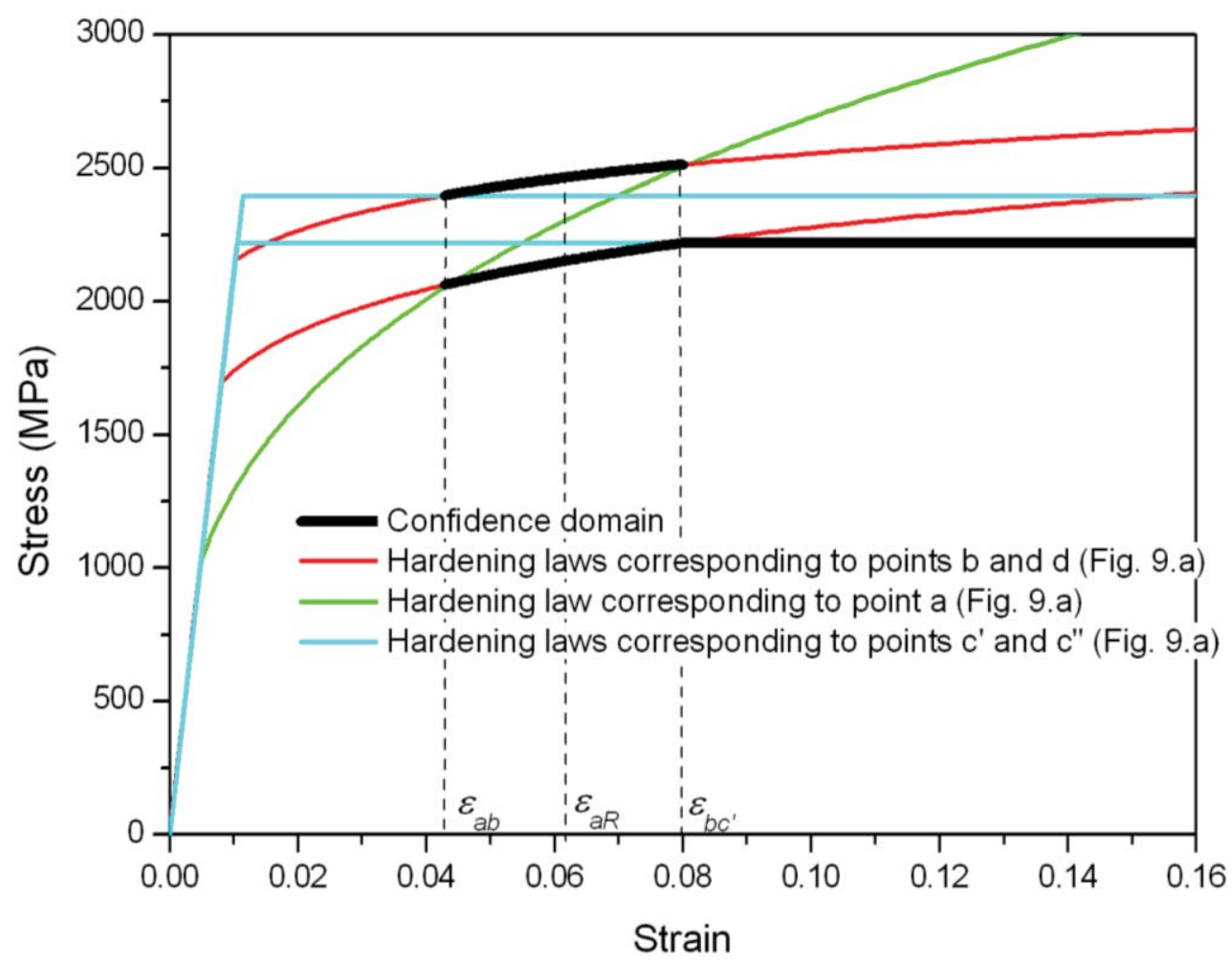

Figure 9.b : Confidence domain with limit hardening laws corresponding to Figure 9.a

The confidence domain and the nine hardening laws identified from indentation tests performed on the three studied samples are presented in Fig. 10. This figure shows that the nine identified hardening laws are all located inside the confidence domain. This result validates the fact that the confidence domain includes all possible hardening laws of the carbonitrided surface. 


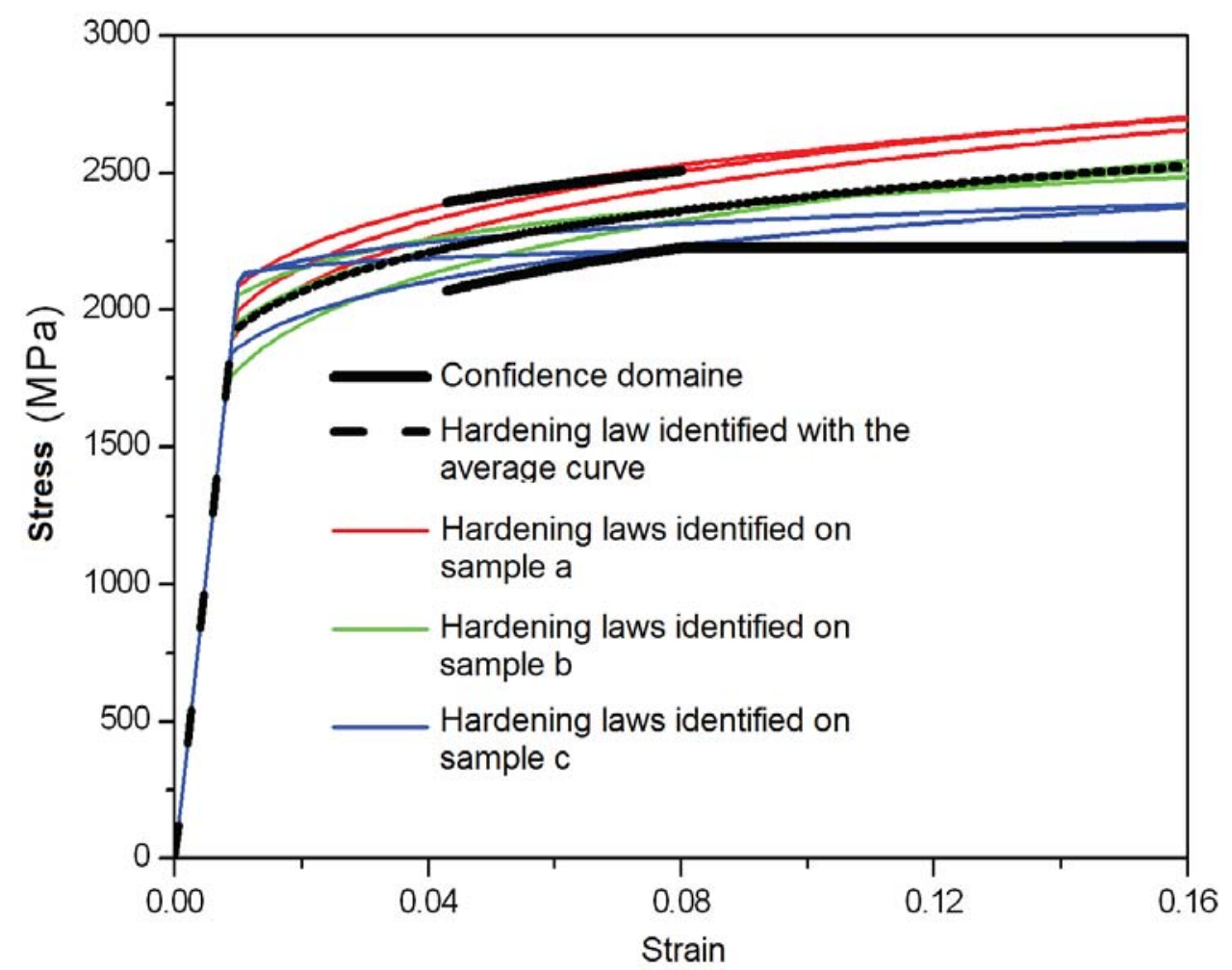

Figure 10: Confidence domain with the nine identified hardening laws from experimental $F-h$ curves.

\section{Understanding the behaviour of carbonitrided steels underneath the indenter: non influence of the friction}

In this study, the friction coefficient between the indenter and the material was set to $\mu=0.1$. One of the main drawbacks of the indentation studies where FE simulations are used, is the chosen values of the friction coefficient. No choice can be physically justified. In this section, we will demonstrate the non influence of the friction coefficient for the spherical indentation of carbonitrided steels with an FE study. The properties of the carbonitrided steel studied above were used: $\sigma_{y}=315 \mathrm{MPa}$ and $n=0.166$ for the substrate; $\sigma_{y}=1990 \mathrm{MPa}$ and $n=0.085$ for the surface; $e_{1}=0.06 \mathrm{~mm}$ and $e_{2}=0.35 \mathrm{~mm}$. The $F-h$ curves obtained from the simulation of the indentation of this material for various values of friction coefficient $\mu$ are presented in Fig. 11. As can be seen in this figure, the friction coefficient has almost no influence on the indentation response for the three studied cases, $\mu=0$ (frictionless contact), $0.1,0.3$. For the case of homogenous materials it was demonstrated that the friction coefficient has a strong influence on the spherical indentation response for large values of penetration depth. 


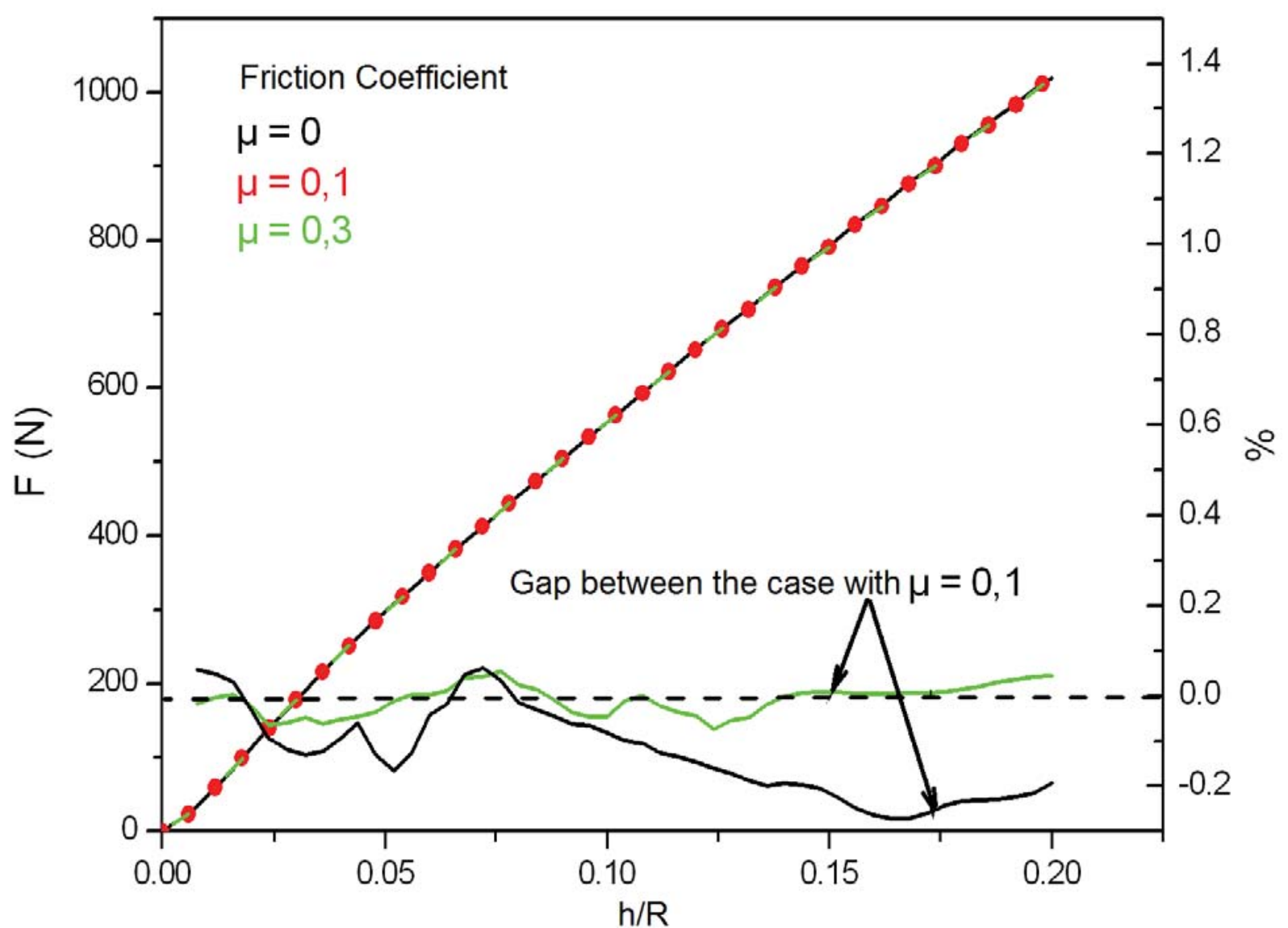

Figure 11 : The three indentation simulated curves $F$ - $h$ with the calculated error between them and the reference $\mu=0.1$

In order to understand the non-influence of the friction coefficient, the radial displacements obtained from FE simulations are plotted in Fig. 12 for homogenous material, and in Fig. 13 for carbonitrided steel. For the homogenous material, Fig. 12 shows that the highest values of radial displacement are in the contact zone between the indenter and the material. This observation explains why the friction has a strong influence on the spherical indentation response of homogeneous materials. The material tries to move horizontally at the contact zone and the friction prevents this displacement. Therefore, the friction has an influence on the pile up formation and on the $F$ - $h$ curve. This influence has already been demonstrated in various studies. For the carbonitrided steels, it can be observed in Fig.. 13 that there is almost no radial displacement in the contact zone. This means that for friction or frictionless conditions, the material does not move horizontally underneath the indenter which explains the non- influence of the friction coefficient for indentation of carbonitrided steels. 

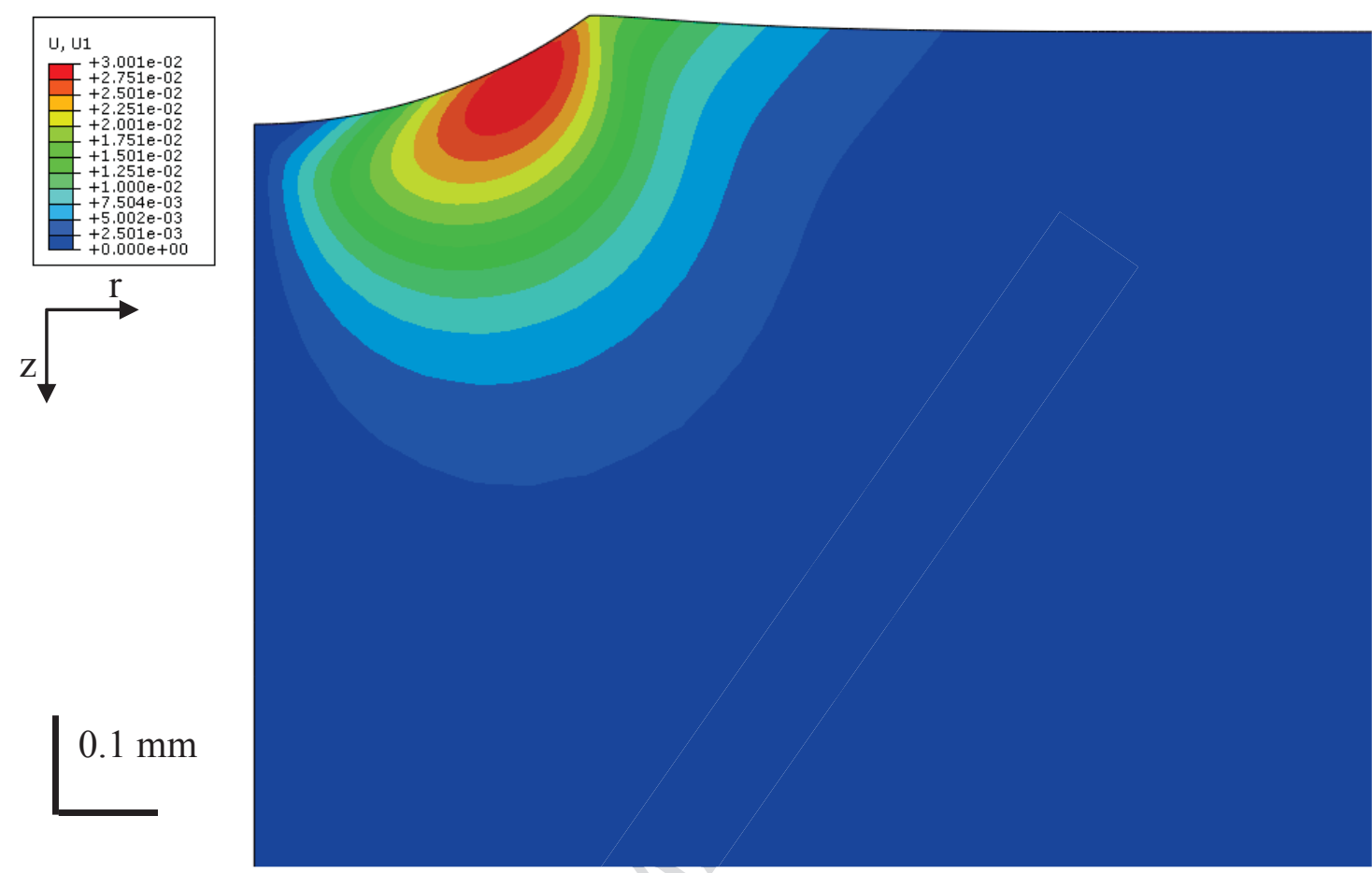

Figure 12: Radial displacement $h_{\max } / R=0.17$ in the case of a homogeneous material $\left(\sigma_{y}=260\right.$

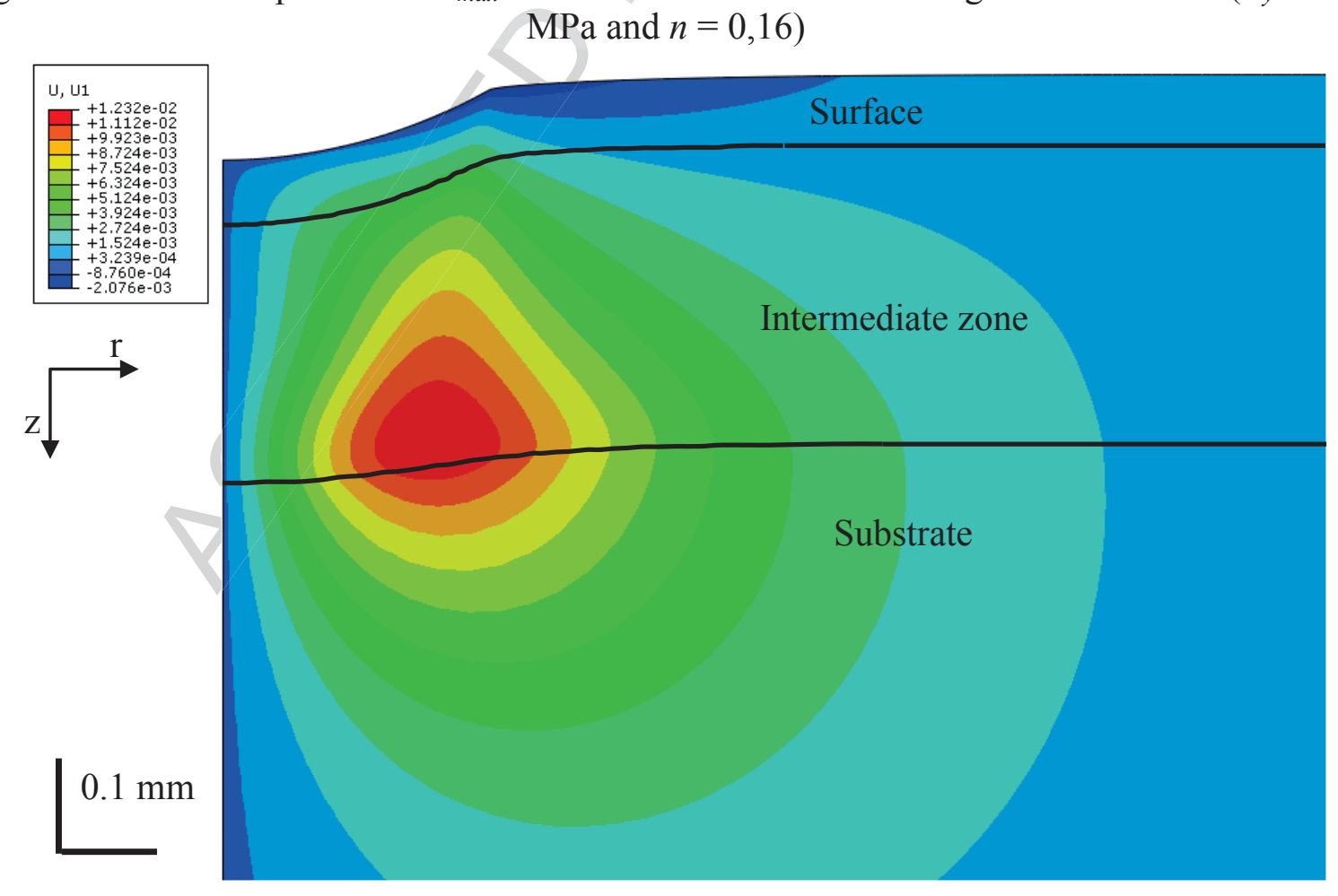

(b)

Figure 13: Radial displacement $h_{\max } / R=0.17$ in the case of a PGM (substrate $\sigma_{y}=315 \mathrm{MPa}$ and $n=0.166$; surface $\sigma_{y}=1990 \mathrm{MPa}$ and $n=0.085 ; e_{1}=0.06 \mathrm{~mm}$ and $e_{2}=0.35 \mathrm{~mm}$ )

Concerning the plastic strain in the material in the case of homogenous material and carbonitrided steel, we observe very large differences. Contrary to the homogenous material for the carbonitrided steel, the yielded zone goes downwards because the underlying material is less resistant than the material at the contact zone. This observation explains why there is 
no radial displacement in the contact zone and also why there is no pile up for the case of carbonitrided steels.

\section{Conclusion}

In previous papers, authors have proposed two methods in order to characterize mechanical properties of carbonitrided steels. When mechanical properties are identified, it is very important to have access to the accuracy of these properties.

In this paper, it was demonstrated that using the concept of the average representative strain proposed in a former paper, provides a confidence domain. The average identified hardening law is surrounded with two border functions which represent the confidence domain. Moreover, a numerical study of the sample behaviour under the indenter has shown the noninfluence of the friction coefficient on the results. In the case of an industrial application, this result demonstrates that identification results will not be perturbed with different friction conditions.

\section{References}

[1] Cao Y.P. and Lu J. A new scheme for computational modeling of conical indentation in plastically graded materials. J. Mater. Res. 19(6) (2004) 1703.

[2] Garnier V. and Corneloup G. Determining of the evolution of the elasticity modulus by surface wave according to the depth in a nitrided layer. Ultrasonics 34 (1996) 401.

[3] Giannakopoulos A.E. Indentation of plastically graded substrates by sharp indentors. Int. J. Solids Struct. 39 (2002) 2495.

[4] J. Wan, A. Fatemi, Int. J. Fatigue 17 (1995) 15-24.

[5] Nayebi A., El Abdi R., Bartier O., and Mauvoisin G. New procedure to determine steel mechanical parameters from the spherical indentation technique. Mech. Mater. 34 (2002) 243.

[6] Collin JM, Mauvoisin G, Bartier O, El Abdi R, Pilvin P. Experimental evaluation of the stress-strain curve by continuous indentation using different indenter shapes. Mater Sci Eng A 501 (2009) 140-5.

[7] Lee H., Lee J.H., and Pharr G.M. A numerical approach to spherical indentation techniques for material property evaluation. J. Mech. Phys. Solids 53 (2005) 2037.

[8] Cao Y.P. and Lu J. A new method to extract the plastic properties of metal materials from an instrumented spherical indentation loading curve. Acta Mater. 52 (2004) 4023.

[9] Ogasawara N., Chiba N., and Chen X. Measuring the plastic properties of bulk materials by indentation test. Scr. Mater. 54 (2006) 65.

[10] Zhao M., Ogasawara N., Chiba N., and Chen X. A new approach to measure the elasticplastic properties of bulk materials using spherical indentation. Acta Mater. 54 (2006) 23.

[11] Nakamura T, Wang T, Sampath S. Determination of properties of graded materials by inverse analysis and instrumented indentation. Acta Mater 48 (2000) 4293-306.

[12] Bolzon G, Maier G, Panico M. Material model calibration by indentation, imprint mapping and inverse analysis. Int J Solid Struct 41 (2004) 2957-75.

[13] Huber N, Tsakmakis Ch. Determination of constitutive properties from spherical indentation data using neural networks. Part II: plasticity with non linear isotropic and kinematic hardening. J Mech Phys Solid 47 (1999) 1589-607.

[14] Collin J.-M., Parenteau T., Mauvoisin G. and Pilvin P. Material parameters identification using experimental continuous spherical indentation for cyclic hardening. Computational Materials Science 46 (2009) 333-338

[15] Collin J.-M., Mauvoisin G. and Pilvin P. Materials characterization by instrumented indentation using two different approaches. Materials and Design 31 (2010) 636-640 
[16] D. Tabor, Hardness of Metals, Clarendon Press, Oxford, 1908.

[17] Cheng Y-T. and Cheng C-M. Can stress strain relationship be obtained from indentation curves using conical and pyramidal indenters? J. Mater. Res. 14(9) (1999) 3493

[18] M. Dao, N. Chollacoop, K.J. Van Vliet, T.A. Venkatseh, S. Suresh, Acta Mater. 49 (2001) 3899-3918.

[19] N. Chollacoop, M. Dao, S. Suresh, Acta Mater. 51 (2003) 3713-3729.

[20] Hernot. X., Moussa C., Bartier O. Study of the concept of representative strain and constraint factor introduced by Vickers indentation. Mechanics of Materials 2014, 68:1-14.

[21] Moussa C., Hernot X., Bartier O., Delattre G., Mauvoisin G. Identification of the hardening law of materials with spherical indentation using the average representative strain for several penetration depths. Materials Science and Engineering A 2014, 606:409-416 [22] Moussa C., Bartier O., Mauvoisin G., Pilvin P. and Delattre G. Characterization of homogenous and plastically graded materials with spherical indentation and inverse analysis. Journal of Materials and Research 27 (1) (2012) 20-27.

[23] Choi I.S., Dao M., and Suresh S. Mechanics of indentation of plastically graded materials-I: Analysis. J. Mech. Phys. Solids 56 (2008) 157.

[24] Choi I.S., Detor A.J., Schwiger R., Dao M., Schuh C.A., and Suresh S. Mechanics of indentation of plastically graded materials-II: Experiments on nanocrystalline alloys with grain size gradients. J. Mech. Phys. Solids 56 (2008) 172.

[25] Gao X.L., Jing X.N., and Subhash G. Two new expanding cavity models for indentation deformations of elastic strain-hardening materials. Int. J. Solids Struct. 43 (2006) 2193.

[26] Moussa C., Bartier O., Mauvoisin G., Hernot X., Collin J.-M., Delattre G. Experimental and numerical investigation on carbonitrided steel. Surface and Coatings Technology 2014, 258: $782-787$.

[27] P. Pilvin, Phd thesis, Université Pierre et Marie Curie, 1990.

[28] Moussa C., Hernot X., Bartier O., Delattre G, Mauvoisin G. Evaluation of the tensile properties of a material through spherical indentation: definition of an average representative strain and a confidence domain. Journal of material science 2014, 258: 592-603.

[29]P. Brammer, X. Hernot, G. Mauvoisin, O. Bartier, S. S. Sablin. A method to take account of the geometrical imperfections of quasi-spherical indenters. Materials and Design, Vol. 49 , pp.406-413 (2013). 


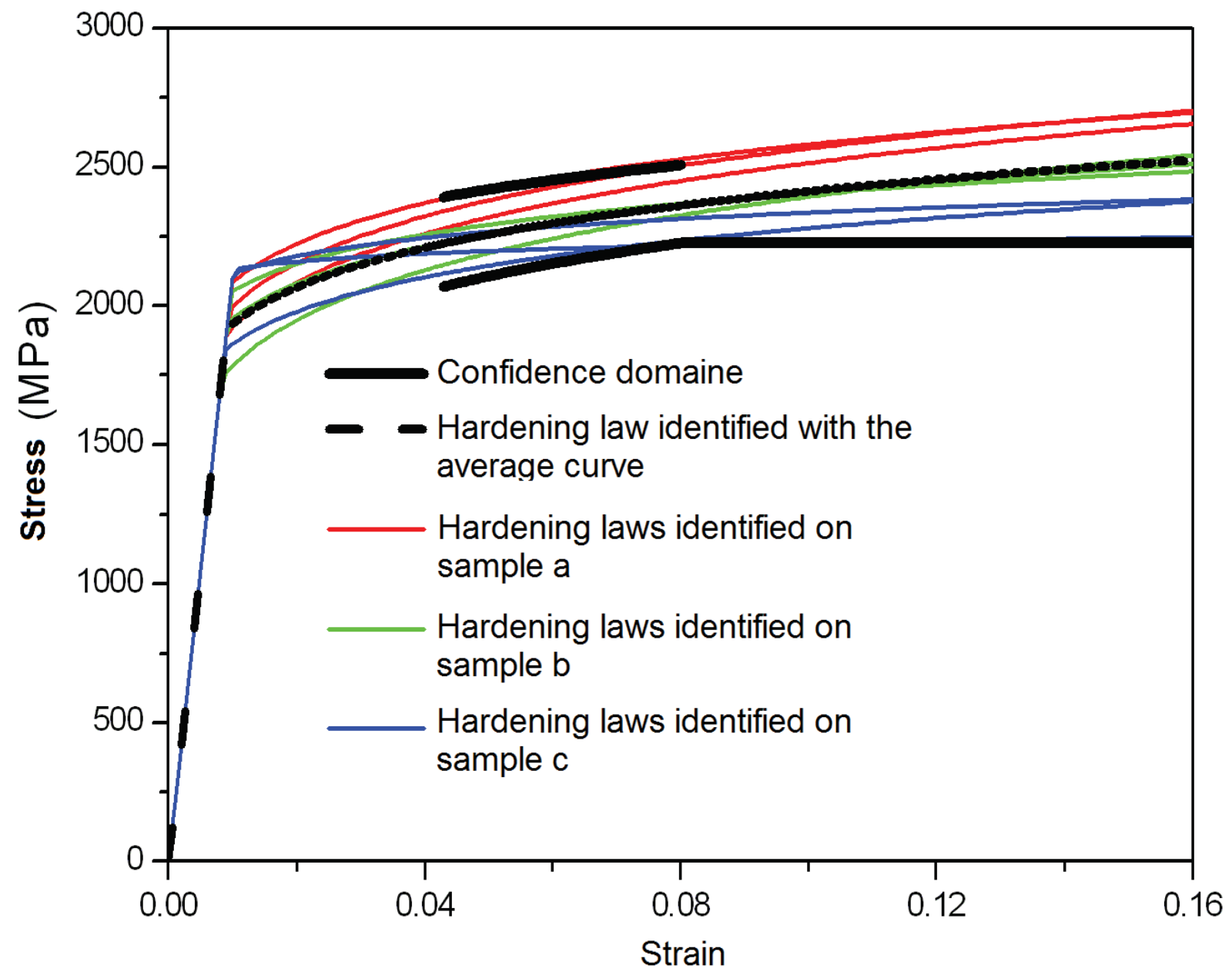

Graphical abstract 